\title{
Digital mapping of soil organic carbon stocks in Ukraine
}

\author{
K.V. Viatkin ${ }^{1}$, Y.V. Zalavskyi², V.V. Lebed ${ }^{2 *}$, O.I. Sherstyuk ${ }^{2}$, O.M. Bihun², \\ I.V. Plisko², S.G. Nakisko²
}

${ }^{1}$ Global Soil Partnership Secretariat, Food and Agriculture Organization of the United Nations, Rome, Italy ${ }^{2}$ NSC "Institute for Soil Science and Agrochemistry Research named after O.N. Sokolovsky", Kharkiv, Ukraine

\begin{tabular}{|c|c|}
\hline ARTICLE INFO & ABSTRACT \\
\hline $\begin{array}{l}\text { Received 02.07.2019 } \\
\text { Received in revised form } \\
22.07 .2019 \\
\text { Accepted 19.08.2019 } \\
\text { Available online } 01.09 .2019\end{array}$ & $\begin{array}{l}\text { Aim. Create a digital map of organic carbon stocks in the soils of Ukraine using digital } \\
\text { soil mapping technologies. Methods. To create a digital map, spatial prediction } \\
\text { methods were applied using } R \text { programming language. Results. Based on } \\
\text { information on the organic carbon content in soil of Ukraine, legacy soil maps, remote } \\
\text { sensing materials and additional topographic and climatic characteristics using the } \\
\text { digital mapping technology, a national digital map of soil organic carbon stocks in a } 0 \text { - } \\
30 \mathrm{~cm} \text { layer with a resolution of } 1 \times 1 \mathrm{~km} \text { was created. Modelling of the spatial } \\
\text { distribution of organic carbon stocks in mineral soils was performed using the }\end{array}$ \\
\hline $\begin{array}{l}\text { Keywords: } \\
\text { digital soil mapping; } \\
\text { Global Soil Organic Carbon } \\
\text { Map; } \\
\text { GSOCmap; } \\
\text { organic carbon; } \\
\text { soil cover of Ukraine }\end{array}$ & $\begin{array}{l}\text { Random Forest algorithm, in peat lands - using the kriging method. The most } \\
\text { significant predictors for spatial distribution of soil organic carbon stocks in the } \\
\text { country's soil cover were soil type, climate variables, spectral reflectance of bare soil } \\
\text { in the near infrared range of the spectrum. Conclusions. The digital map of organic } \\
\text { carbon stocks in Ukraine's soils was developed in accordance with the specifications } \\
\text { of the Global Soil Partnership of the United Nation Food and Agriculture Organization } \\
\text { (FAO) and integrated into the FAO Global Soil Organic Carbon Map (GSOCmap). } \\
\text { The created national digital map of carbon stocks in the soils of Ukraine can be used } \\
\text { as a basis for further monitoring of organic carbon stocks, however, this task can be } \\
\text { achieved only if a unified national soil information system is created, in which } \\
\text { information on field surveys is accumulated and updated. }\end{array}$ \\
\hline
\end{tabular}

Citing: Viatkin K.V., Zalavskyi Y.V., Lebed V.V., Sherstyuk O.I., Bihun O.M., Plisko I.V., Nakisko S.G. 2019. Digital mapping of soil organic carbon stocks in Ukraine. Agrochemistry and Soil Science. Collected papers. No. 88. Kharkiv: NSC ISSAR, P. 5-11. DOI: https://doi.org/10.31073/acss88-01

\section{References}

1. Lal R. 2016. Soil health and carbon management. Food and Energy Security. 5(4):212-222.

2. Status of the World's Soil Resources (SWSR) - Main Report. Rome, FAO and ITPS.2015; 650 p.

3. Hiederer R., Köchy M. 2011. Global Soil Organic Carbon Estimates and the Harmonized World Soil Database. Luxembourg, Publications Office of the European Union. $79 \mathrm{p}$.

4. GSP Guidelines for sharing national data/information to compile a Global Soil Organic Carbon (GSOC) map. Rome, FAO. 2016. 25 p.

5. Soil Organic Carbon Mapping Cookbook. 2nd edition. Ed Yigini Y., Olmedo G.F., Reiter S., Baritz R., Viatkin K., Vargas R. Rome, FAO. 2018. 220 p.

6. Medvedev V.V., Plysko I.V., Bihun O.M. 2015. Experience of pedotransfer modelling in the soil physics researches. Bulletin of Agricultural Science. 1:17-24. (Ukr.).

7. Medvedev V.V., Laktionova T.M., Plisko I.V., Bihun O.M., Sheiko S.M., Nakisko S.G. 2012. Agronomy-oriented arable lands' zoning-division per soil properties (substantiation, methods and examples). Kharkiv: City printing house. 100 p. (Ukr.).

8. Truskavetsky R.S. 2010. Peat soils and peat lands of Ukraine. Kharkiv: Miskdruk. 277 p. (Ukr.).

9. McBratney A.B., Mendonça Santos M.L., Minasny B. 2003. On digital soil mapping. Geoderma. 117(1-2):3-52.

10. Conrad O., Bechtel B., Bock M., Dietrich H., Fischer E., Gerlitz L., Wehberg J., Wichmann V., Boehner J. 2015. System for Automated Geoscientific Analyses (SAGA) v. 2.1.4. Geoscientific Model Development. 8(7):1991-2007.

11. Guisan A., Weiss S.B., Weiss A.D. 1999. GLM versus CCA spatial modeling of plant species distribution. Plant Ecology. 143(1):107-122.

12. Truskavetsky S.R. 2003. Modern approaches to mapping of soil cover of Ukrainian Polissya. Bulletin of Kharkiv national agrarian university named after V.V. Dokuchayev. 1:120-124. (Ukr.). (Ukr.).

13. Polupan M.I., Solovey V.B., Velichko V.A. Classification of Ukrainian soils. Kyiv: Agrarian Science. 2005. 298 p.

14. Hijmans R.J., Cameron S.E., Parra J.L., Jones P.G., Jarvis A. 2005. Very high resolution interpolated climate surfaces for global land areas. International Journal of Climatology. 25(15):1965-1978.

15. Malone B.P., Minasny B., McBratney A.B. 2017. Using R for Digital Soil Mapping. Switzerland, Springer. 262 p.

16. Breiman L. Bagging predictors. 1996. Machine Learning: 24(2):123-140.

17. Global Soil Organic Carbon Map (GSOCmap). Technical Report. Rome, FAO and ITPS. 2018. 162 p.

УДК 004.9:631.4(477)

Цифрове картографування запасів органічного вуглецю у ґрунтах України 
${ }^{1}$ Секретаріат Глобального ґрунтового партнерства, Продовольчої та сільськогосподарської організації ООН, Рим, Італія

${ }^{2}$ НHЦ «Інститут ґрунтознавства та агрохімії імені О.Н. Соколовського», Харків, Україна

\begin{tabular}{|c|c|}
\hline ІНФОРМАЦІЯ & АНОТАЦІЯ \\
\hline $\begin{array}{l}\text { Отримано } 02.07 .2019 \\
\text { Отримано після } \\
\text { доопрацювання } \\
22.07 .2019 \\
\text { Затверджено до друку } \\
19.08 .2019 \\
\text { Доступно онлайн } \\
01.09 .2019\end{array}$ & $\begin{array}{l}\text { Метою роботи було створення цифрової карти запасів органічного вуглецю в ґрунтах } \\
\text { України із застосуванням технологій цифрового картографування ґрунтів. Для } \\
\text { створення цифрової карти були застосовані методи просторового прогнозування із } \\
\text { використанням мови програмування R. Результати. На основі інформації про вміст у } \\
\text { ґрунтах України органічного вуглецю, архівних ґрунтових карт, матеріалів } \\
\text { дистанційного зондування та додаткових топографічних і кліматичних характеристик із } \\
\text { використанням технологій цифрового картографування була створена національна } \\
\text { цифрова карта запасів ґрунтового органічного вуглецю у шарі 0-30 см із роздільною }\end{array}$ \\
\hline $\begin{array}{l}\text { Ключові слова: } \\
\text { Глобальна карта } \\
\text { запасів грунтового } \\
\text { органічного вуглецю; } \\
\text { GSОСтар; } \\
\text { грунтовий покрив } \\
\text { України; } \\
\text { органічний вуглець; } \\
\text { цифрове } \\
\text { картографування } \\
\text { грунтів. }\end{array}$ & 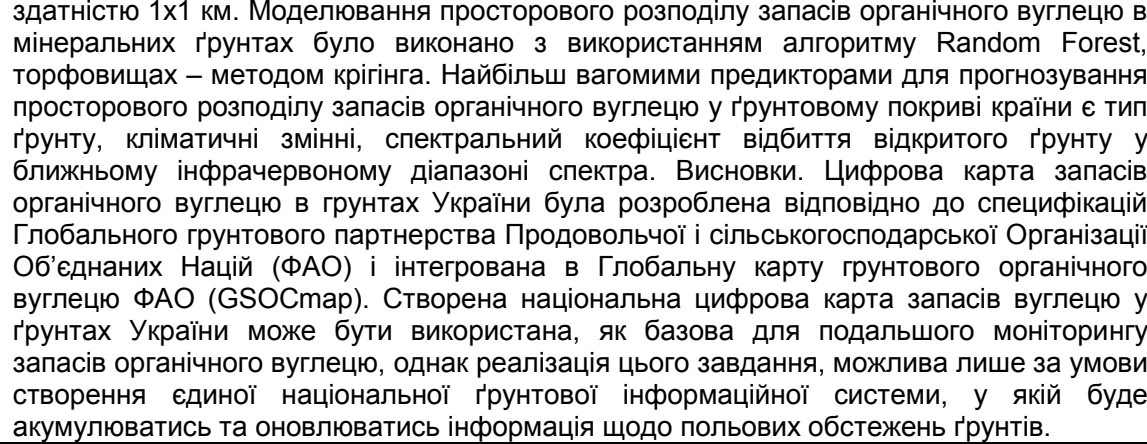 \\
\hline
\end{tabular}

Форма иитування: Digital mapping of soil organic carbon stocks in Ukraine / K.V. Viatkin, Yu.V. Zalavskyi, V.V. Lebed [et. al] Agrochemistry and Soil Science. Collected papers. 2019. No. 88. Kharkiv: NSC ISSAR, P. 5-11. DOI: https://doi.org/10.31073/acss88$\underline{01}$

\section{Список використаних джерел}

1. Lal R. Soil health and carbon management. Food and Energy Security. 2016. 5(4):212-222.

2. Status of the World's Soil Resources (SWSR) - Main Report. Rome, FAO and ITPS.2015; 650 p.

3. Hiederer R., Köchy M. Global Soil Organic Carbon Estimates and the Harmonized World Soil Database. Luxembourg, Publications Office of the European Union. 2011. 79 p.

4. GSP Guidelines for sharing national data/information to compile a Global Soil Organic Carbon (GSOC) map. Rome, FAO. 2016. 25 p.

5. Soil Organic Carbon Mapping Cookbook. 2nd edition. Ed Yigini Y., Olmedo G.F., Reiter S., Baritz R., Viatkin K., Vargas R. Rome, FAO. 2018. 220 p.

6. Медведєв В.В., Пліско І.В., Бігун О.М. Досвід педотрансферного моделювання у дослідженнях фізики грунтів. Вісник аграрної науки. 2015. № 1. С. 17-24.

7. Агрономічно орієнтоване районування земель за властивостями грунтів (обґрунтування, методи, приклади) /В.В.Медведєв, Т.М. Лактіонова, І.В. Пліско, [та ін.]. Харків: Міська друкарня, 2012. 100 с.

8. Трускавецький Р.С. Торфові грунти і торфовища України. Харків: Міська друкарня, 2010. 278 с.

9. McBratney A.B., Mendonça Santos M.L., Minasny B. On digital soil mapping. Geoderma. 2003. 117(1-2):3-52.

10. Conrad O., Bechtel B., Bock M., Dietrich H., Fischer E., Gerlitz L., Wehberg J., Wichmann V., Boehner J. 2015. System for Automated Geoscientific Analyses (SAGA) v. 2.1.4. Geoscientific Model Development. 8(7):1991-2007.

11. Guisan A., Weiss S.B., Weiss A.D. GLM versus CCA spatial modeling of plant species distribution. Plant Ecology. 1999. 143(1):107-122.

12. Трускавецький С.Р. Сучасні підходи до картографування грунтового покриву Полісся. Вісник ХНАУ. 2003. № 1. С. $120-124$.

13. Полупан М.І., Соловей В.Б., Величко В.А. Класифікація грунтів України. Київ: Аграрна наука, 2005. 298 с.

14. Hijmans R.J., Cameron S.E., Parra J.L., Jones P.G., Jarvis A. Very high resolution interpolated climate surfaces for global land areas. International Journal of Climatology. 2005. 25(15):1965-1978.

15. Malone B.P., Minasny B., McBratney A.B. Using R for Digital Soil Mapping. Switzerland, Springer. 2017. 262 p.

16. Breiman L. Bagging predictors. 1996. Machine Learning: 24(2):123-140.

17. Global Soil Organic Carbon Map (GSOCmap). Technical Report. Rome, FAO and ITPS. 2018. 162 p.

УДК 004.9:631.4(477)

Цифровое картографирование запасов органического углерода в почвах Украины

К.В. Вяткин ${ }^{1}$, Ю.В. Залавский ${ }^{2}$ В.В. Лебедь ${ }^{\star 2}$, О.И. Шерстюк ${ }^{2}$ О.Н. Бигун ${ }^{2}$, И.В. Плиско ${ }^{2}$, С.Г. Накисько

${ }^{1}$ Секретариат Глобального почвенного партнерства, Продовольственная и сельскохозяйственная организация ООН, Рим, Италия 
${ }^{2}$ Национальный научный центр «Институт почвоведения и агрохимии имени А.Н. Соколовского», Харьков, Украина

\section{*E-mail: swdiscover@gmail.com}

Цель. Создать цифровую карту запасов органического углерода в почвах Украины с применением технологий цифрового картографрирования почв. Методы. Для создания цифровой карты были применены методы пространственного прогнозирования с использованием языка программирования R. Результаты. На основе информации о содержании в почве Украины органического углерода, архивных почвенных карт, материалов дистанционного зондирования и дополнительных топографических и климатических характеристик с использованием технологий цифрового картографирования была создана национальная цифровая карта запасов почвенного органического углерода в слое 0-30 cм с разрешением 1х1 км. Моделирование пространственного распределения запасов органического углерода в минеральных почвах было выполнено с использованием алгоритма Random Forest, торфяннках - методом кригинга. Наиболее весомыми предикторами для прогнозирования пространственного распределения запасов органического углерода в почвенном покрове страны стали тип почвы, климатические переменные, спектральный коэффициент отражения открытого грунта в ближнем инфракрасном диапазоне спектра. Выводы. Цифровая карта запасов органического углерода в почвах Украины была разработана в соответствии со спецификациями Глобального почвенного партнерства Продовольственной и сельскохозяйственной Организации Объединенных Наций (ФАО) и интегрированная в Глобальную карту почвенного органического углерода ФАО (GSOCmap). Созданная национальная цифровая карта запасов углерода в почвах Украины может быть использована, как базовая для дальнейшего мониторинга запасов органического углерода, однако реализация этой задачи возможна только при условии создания единой национальной почвенной информационной системы, в которой будет аккумулироваться и обновляться информация о полевых обследованиях почв.

Ключевые слова: цифровое картографрирование почв; органический углерод; почвенный покров Украины; Глобальная карта запасов почвенного органического углерода; GSOCmap. 